\title{
The Capability of Hydrilla as a Phytoremediator for River Water
}

\author{
Asma Ali Moubark, Lukman Hakim, Amin Setyo Leksono \\ ${ }^{1}$ Department of Environmental Resources Management, Post-Graduate Program, Brawijaya University, Indonesia \\ ${ }^{2}$ Department of Chemistry, Faculty of Mathematics and Natural Sciences, University of Brawijaya, Indonesia \\ ${ }^{3}$ Department of Biology, Faculty of Mathematics and Natural Sciences, University of Brawijaya, Indonesia
}

\begin{abstract}
The aim of this study is to investigate the feasibility of Hydrilla as a phytoremediator to improve the quality of river water samples collected from Brantas River, Malang, Indonesia. The phytoremediation process is carried out in static river water samples, and the results show that Hydrilla is capable to augment the reduction the nitrite and ammonia content in the samples, while leaving nitrate and phosphate unaffected within the constraints of the study.
\end{abstract}

Keywords: Ammonia, Hydrilla, Nitrite, Phytoremediation, River Water

\section{INTRODUCTION}

Aquatic environment, such as river water, in developing countries is often taken as a recipient of domestic and agricultural waste [1]. The continuous increase of activities in both sectors directly affecting the quality of nearby river water by shifting its composition. The leak of fertilizer in agricultural activities, as an example, can increase nitrogen and phosphorus content in river water. Although both elements are classified as nutrients, their amount in excessive can be considered as "pollutant" that brings harmful impact to aquatic environment, such as eutrophication [2]. In addition, the toxicity of certain nutrients depends on their oxyanion form, such as nitrite is known to be hazardous to human health for being carcinogenic and can interfere with oxygen uptake in Hemoglobin [3]. At the same time, river water also serves as the main supply for tap and drinking water. For example, the tap and drinking water which are distributed in Malang area, Indonesia, are mainly supplied from Brantas river. Therefore, maintaining the quality of river water in the middle of growing domestic and agricultural activities is indispensable.

The term of phytoremediation is used for the use of natural or genetically modified plants that capable to normalize the environment medium, such as soil [4] and water [5]. The method is considered advantageous in the view

\footnotetext{
Correspondence address:

Amin Setyo Leksono

Email : amin28@ub.ac.id

Address : Post-graduate Program, University of Brawijaya
}

of long-term ecological impact and cost efficiency. Rooted aquatic plants is known for its ability to bind considerable amount of nutrients with their root system. Among the family, Hydrilla (Hydrilla verticillata) is native to warm water environment and largely available across Indonesia. Hydrilla has been reported to be able to bind toxic metals such as Cadmium [6,7], Chromium [8,9], and Arsenic $[10,11]$, which shows its capability as a potential phytoremediator.

Regardless of the extensive reports of Hydrilla capability in binding toxic metals, the capability of Hydrilla to improve the condition of nutrients, such as nitrogen and phosphorus, in river water is scarcely reported. This study is aimed to investigate the capability of Hydrilla as a phytoremediator to improve the quality of river water sampled from Brantas river, Malang, Indonesia.

\section{MATERIALS AND METHODS}

Water and hydrilla samples

River water samples were collected from Brantas river in Malang area. The samples were used as river water matrix for the phytoremediation study, and it was not intended to describe the actual content of organic matters in Brantas river. Hydrilla plant was purchased from local vegetation market and washed prior to phytoremediation process.

\section{Phytoremediation procedure}

Four liter of river water was placed in a plastic container, and $25 \mathrm{~g}$ of Hydrilla was immersed into the water. The effect of phytoremediation was monitored by analyzing the concentration of nitrate, nitrite, ammonia, and phosphate every two days; i.e. 
The Capability of Hydrilla as a Phytoremediator for River Water (Moubark, et al.)

$25 \mathrm{~mL}$ of water was sampled for analysis at day 0 , $2,4,6$, and 8 . As a control, four liter of river water was placed in a plastic container in the absence of Hydrilla and subjected to the same analysis.

\section{Nitrogen and phosphorus determination}

The determination of nitrogen and phosphorus in their common anionic forms was carried out in Laboratory of Department of Chemistry, Brawijaya University, Indonesia. The concentration of nitrite, nitrate, ammonia, and phosphate were determined by spectrophotometric method, each respectively based on reaction with KID reagent, phenoldisulfonic acid, Nessler reagent, and ammonium molybdate complex.

\section{RESULTS AND DISCUSSION}

The phytoremediation process in this study was carried out in static river water samples. While the procedure may cast doubt to its relevancy with the continuously flowing river water, the phytoremediation has been shown to be finely applicable in the flowing water [12]. In addition, considering that most of tap water in Malang area is supplied from Brantas river, it is plausible to consider a static phytoremediation procedure to improve the river water quality in tap water treatment installation.

Figure 1 shows the change in nitrite and nitrate concentration in river water samples over the course of pythoremediation process with Hydrilla, and also river water samples in the absence Hydrilla as the control. In both case, a decrease in concentration of nitrite over the days can be observed. Initially, we considered that nitrite can be rapidly oxidized to nitrate in the presence of free oxygen. However, Figure 1 evidently shows a difference in the rate of nitrite depletion in the presence of Hydrilla, which suggests the role of phytoremediation with Hydrilla in reducing the nitrite concentration. Moreover, the increase of nitrate concentration, which is supposed to be product of nitrite oxidation, did not proceed at different rate for both cases. This further confirms that the mechanism of nitrite depletion is not simply due to the oxidation by free oxygen.

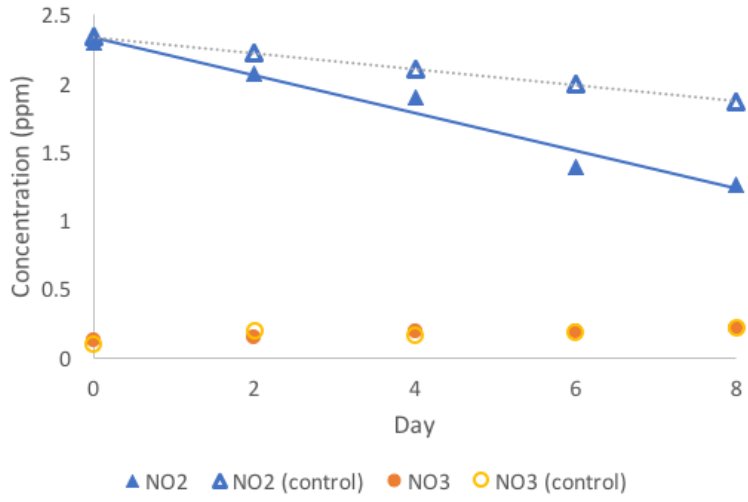

Figure 1. The concentration of $\mathrm{NO}_{2}{ }^{-}$and $\mathrm{NO}_{3}{ }^{-}$in river water samples $(n=3)$ during the phytoremediation process with Hydrilla. The straight lines show a linear interpolation whose gradient is related to the rate of nitrite decreasing rate.

Ammonia as the other form of nitrogen content in river water was taken into account during the monitoring of phytoremediation process, and the change in ammonia concentration over the days is shown in Figure 2. The decrease of ammonia content, among the various possibilities, can be attributed to the nitrification by microbial activity. However, here the concentration of ammonia was found to rapidly decrease over the first two days in the presence of Hydrilla, which further suggests the role of phytoremediation with Hydrilla in reducing the concentration of ammonia in river water sample. Overall, the concentration of ammonia is lower compared to the case without Hydrilla. The change ammonia, nitrite, and nitrate concentration in the control samples, as shown in Figure 1 and Figure 2, supports the two-steps nitrification process of ammonia to nitrite and nitrate by microbial activity, subsequently. This relation, however, cast uncertainty to the mechanism of ammonia and nitrite suppression by phytoremediation with Hydrilla. The relatively unchanged concentration of nitrate for both cases, with and without Hydrilla, further demand a more detail study, which is not covered in this study. 


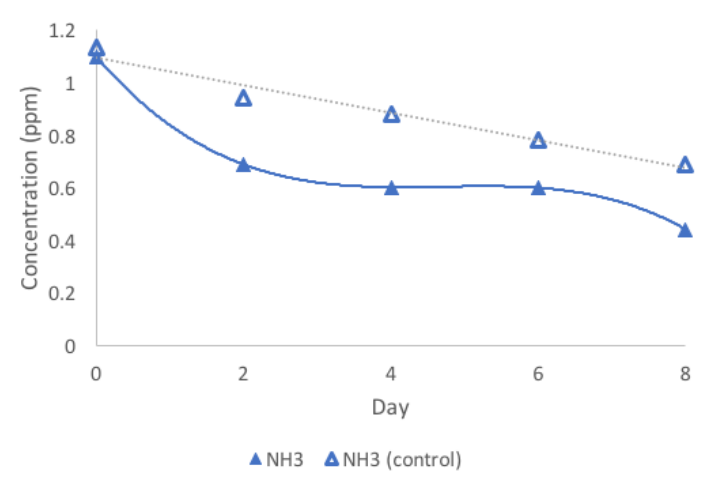

Figure 2. The concentration of $\mathrm{NH}_{3}$ in river water samples $(n=3)$ during the phytoremediation process with Hydrilla. The bold curve shows a thirdorder polynomial fitting; which, although poor as a model, depicts the rate of ammonia depletion over the course of phytoremediation.

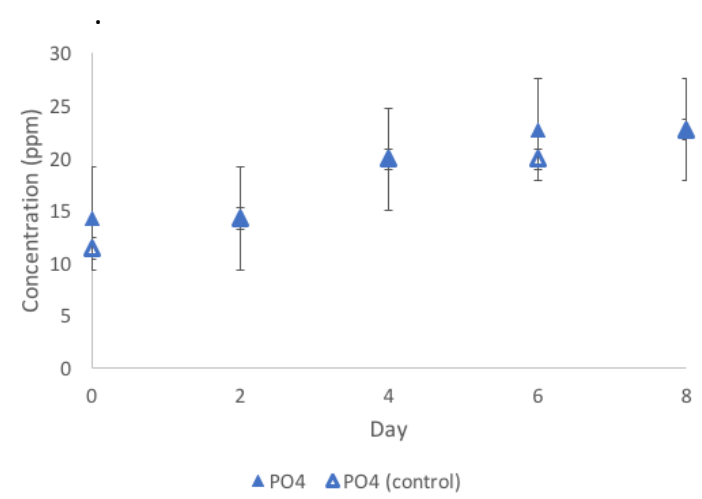

Figure 3. The concentration of $\mathrm{PO}_{4}{ }^{3-}$ in river water samples $(n=3)$ during phytoremediation process with Hydrilla. The error bars show the standard deviation of the averaged results.

We attempted to investigate the influence of phytoremediation process with Hydrilla to phosphate concentration in river water, and the results are shown in Figure 3 . In the absence of sediment in the both samples, the change of phosphate concentration can be attributed to the product of microbial activity. While it is visible that phosphate concentration is increasing over the time, the influence of Hydrilla to the phosphate content in river water samples is hardly evident. In both treatments, with and without Hydrilla, the concentration of phosphate is shown to be indifferent over the course of time. Even the differences at day 0 and 6 are within the uncertainty in determination method, as evident from their standard deviation value. A more robust analytical method for phosphate determination is required to further clarify the issue; which, unfortunately, cannot be carried out due to the constraints of this study

\section{CONCLUSION}

The presence of Hydrilla in river water samples is shown to augment the decrease of nitrite and ammonia content, while leaving the nitrate and phosphate content unaffected within the constraints of this study. The results show the capability of Hydrilla as a phytoremediator, in particular, to improve nitrogen condition for river water.

\section{REFERENCES}

[1] T. Sikder, M. Yasuda, S. M. Syawal, T. Saito, and S. Tanaka, Int. J. Environ. Prot. 2, 8 (2012).

[2] D. J. Conley, H. W. Paerl, R. W. Howarth, D. F. Boesch, S. P. Seitzinger, K. E. Havens, C. Lancelot, and G. E. Likens, Science (80-. ). 323, 1014 (2009).

[3] I. A. Wolff and A. E. Wasserman, Science (80-. ). 177, (1972).

[4] A. Mahar, P. Wang, A. Ali, M. K. Awasthi, A. H. Lahori, Q. Wang, R. Li, and Z. Zhang, Ecotoxicol. Environ. Saf. 126, 111 (2016).

[5] R. Verma and S. Suthar, Alexandria Eng. J. 54, 1297 (2015).

[6] M. Chen, L.-L. Zhang, Y.-C. Tuo, X.-J. He, J. Li, and Y. Song, Ecol. Eng. 96, 178 (2016).

[7] S. Bunluesin, M. Kruatrachue, P. Pokethitiyook, S. Upatham, and G. R. Lanza, J. Biosci. Bioeng. 103, 509 (2007).

[8] A. Mishra, B. D. Tripathi, and A. K. Rai, Ecotoxicol. Environ. Saf. 132, 420 (2016).

[9] L. Li, Y. Li, L. Cao, and C. Yang, Carbohydr. Polym. 125, 206 (2015).

[10] S. Srivastava, S. Sounderajan, A. Udas, and P. Suprasanna, Ecol. Eng. 73, 297 (2014).

[11] M. A. Rahman and H. Hasegawa, Chemosphere 83, 633 (2011).

[12] J. Marrugo-Negrete, G. Enamorado-Montes, J. Durango-Hernandez, J. Pinedo-Hernandez, and S. Diez, Chemosphere 167, 188 (2017). 